\title{
Strategies for epilepsy control in public health aspects
}

Shichuo Li $i^{1^{*}}$, Ding Ding ${ }^{1,2}$ and Xiaoyan Liu ${ }^{1,3}$

\begin{abstract}
This article provides the authors' recommendations of strategies for epilepsy control in public health aspects. Besides a brief review of some collaborative epilepsy control activities in public health aspects by the International League against Epilepsy (ILAE), the International Bureau for Epilepsy (IBE) and the World Health Organization (WHO), recommendations for further developing strategies for epilepsy control in public health aspects to the ILAE, IBE, state governments and other international \& regional governmental organizations and non-governmental organizations are described in the paper including public health strategies/actions in political and geographical aspects and in technological field.
\end{abstract}

Keywords: Epilepsy, Prevention \& control, Public health

\section{Introduction and background}

The advancement in the diagnosis, treatment and research of epilepsy has been accelerated recently, which has greatly brightened the therapeutic outlook for people with epilepsy (PWE). Of equal significance has been the increasing realization of the importance of preventive and community aspects of the disease since 1950's [1]. In 2012, the US Institute of Medicine (IOM) released a seminal report on the public health dimensions of the epilepsies, recommending actions in 7 domains [2].

However, equity and equality in medical services and caring for PWE in the world are far not yet achieved, as shown in widespread existing treatment gap and insufficient accessibility to anti-epileptic drugs (AEDs). Reducing stigma, raising quality of life and social welfare for PWE need continuing attention and more action. A very positive factor for improving epilepsy control in public health aspects is the resolution WHA68.20 which passed in May 2015 by the World Health Organization (WHO) [3]. ${ }^{1}$

By the observation of the authors, training of part-time neurologists, general practitioners (GP) on modern techniques for epilepsy diagnosis/treatment and defining of

${ }^{1}$ https://www.who.int/mental_health/neurology/epilepsy/resolution_6 $8 \_20 /$ en/

* Correspondence: shichuoli@163.com

'China Association Against Epilepsy, Beijing, China

Full list of author information is available at the end of the article working style and responsibilities of epilepsy control in community level are badly needed, especially in low- and middle-income countries (LAMIC) but governments are usually not taking epilepsy control as priority of the public health work and so as many other related social organizations, including international, regional and domestic ones.

This article provides the authors' recommendations of strategies for epilepsy control in public health aspects.

\section{A brief review}

In last two decades, the International League against Epilepsy (ILAE), the International Bureau for Epilepsy (IBE) and the WHO have launched some collaborative epilepsy control activities in public health aspects, which should be highly evaluated:

- Global Campaign against Epilepsy (GCAE): Cosponsored by the IBE, ILAE and WHO started in 1997. The mission of the GCAE was "To improve the acceptability, treatment, services and prevention of epilepsy worldwide". During the year of 2001 to 2005, an Atlas of epilepsy on country resources was published, in which 160 countries participated and covered $98 \%$ of the world population [4]. The regional conferences, reports and declarations completed in all WHO regions. The demonstration projects completed in Senegal, Zimbabwe, Bolivia, Brazil, China, Georgia and started in other 4 
countries. Thereafter, however, the GCAE activities were weakened gradually, except for the ongoing extended rural area epilepsy control project in China, the reason should be further studied.

- The Global Outreach Task Force was set up in 2009, which inherited and extended the job of the GCAE. It's strategic plan includes: (i) to improve the visibility of epilepsy and the activities of the Global Campaign in all countries; (ii) to promote activities of all epilepsy projects on a country and regional level; (iii) to assess and strengthen health care systems for epilepsy; (iv) to increase partnerships and collaboration with other organizations. The achievements and lessons to learn should be reviewed and evaluated.

- In September 2011, collaborating with the ILAE \& IBE, the European Parliament approved the Written Declaration on Epilepsy with direct support from 459 Members of Parliament, 90 more than the minimum required and the highest number received by any declaration in the closing EU term (2009-2014) [5]. The declaration calls for the European Commission and Member States, (i) to encourage research and innovation in the area of prevention and early diagnosis and treatment of epilepsy; (ii) to prioritize epilepsy as a major disease that imposes a significant burden across Europe; (iii) to ensure equal quality of life, including in education, employment, transport and public healthcare, for PWE; and (iv) to introduce appropriate legislation to protect the rights of all people with epilepsy. To follow up the implementation of the Declaration is needed.

- In November 2012, the Pan American Health Organization (PAHO/WHO), the ILAE and the IBE signed a Memorandum of Understanding that binds them in a 10-year-long partnership to deploy the Strategic Plan on Epilepsy in the American continent, which gave an example of WHO regional action on epilepsy control [6].

- At the 65th WHO Western Pacific Regional Committee meeting (65th WPRCM),which was held in Manila, Philippines, October 13-17, 2014, a representative of the IBE (Chairman of the ILAE/IBE Research Advocacy Task Force) made a statement to call for a "WHO Western Pacific Strategic Action for Epilepsy": through coordinated efforts at country level designed to: (i) assess the size of the epilepsy burden and related specificities and needs; (ii) introduce and implement national epilepsy programs and services in accordance with international human rights norms and standards; (iii) minimize the gaps in diagnosis and treatment, by addressing inequalities in care and facilitating access to affordable medicines and other treatments; (iv) enact legislation to protect the rights of people with epilepsy; and (v) establish awareness initiatives to educate the public about the nature of the disease and thereby remove stigmatization. The response and effects of the call, however, were not satisfactory.

- The Resolution WHA68.20 passed in the 68th WHA on May 26th (NID). ${ }^{2}$

All the above-mentioned activities proved the great importance of the political commitment by the state government, international \& regional governmental organizations (GOs) and non-governmental organizations (NGOs) in control of epilepsy through public health measurements.

\section{Recommendations}

For further developing strategies for epilepsy control in public health aspects, we recommend to the ILAE, IBE, state governments and other international \& regional GOs and NGOs:

1. To amend and perfect the goal and mission of epilepsy control in reference to (i) the constitution of WHO and the Resolution WHA68.20; (ii) the health related goals from UN "Open Working Group" on Sustainable Development Goals; (iii) the UN General Assembly's Special Session on Children (May 810 2002): Put children first. ${ }^{5}$

2. Public health strategies/actions in political and geographical aspects

2.1 Utilizing Resolution WHA68.20 to demand for governments' political commitment to support, coordinate epilepsy control actions by ILAE chapters, IBE members and other related social organizations.

The remarkable achievements and experiences of the epilepsy control project in rural China (government's funding for free-of-charge AEDs to treat convulsive epileptic patients) may serve as a model [7].

2.2 Strengthening communication/collaboration with other international GOs and NGOs in epilepsy control policies and actions. Those may include UNDP, UNICEF, ILO; Rotary International, Lions Clubs International; some foundations; etc.

2.3 Utilizing the concept of " The Belt and Road (B\&R)", which is a development strategy proposed by Chinese President Xi Jinping focusing on connectivity and cooperation

${ }^{2}$ https://www.who.int/mental_health/neurology/epilepsy/resolution_6 8_20/en/

${ }^{3}$ https://www.who.int/mental_health/neurology/epilepsy/resolution_6 8 20/en/

${ }^{4}$ https://sustainabledevelopment.un.org/owg.html

${ }^{5} \mathrm{https}$ ://www.unicef.org/specialsession/docs_new/documents/A-RESS27-2E.pdf 
between Eurasian countries, primarily the People's Republic of China, the land-based "Silk Road Economic Belt"(SREB) and the oceangoing "Maritime Silk Road"(MSR). We may use the concept of B\&R to develop the international collaboration among countries in professional exchange, to share epilepsy control experiences and lessons.

3. Public health strategies/actions in technological field:Public health strategies/actions in technological field:

3.1 To encourage epilepsy-related public health researches, including epidemiology, disease burden assessment, epilepsy induced mental comorbidities, suicide, health-economics, preventive intervention, rehabilitation, PWE's quality of life, social welfare/human rights, etc.

3.2 To establish a special parallel session of "public health perspective" at the international/regional/ national congresses on epilepsy. How to mobilize, encourage representatives from public health authorities and facilities, other social organizations (e.g., women \& children, social insurance, etc.) to participate in the congresses needs to be discussed in depth.

3.3 To promote the establishment of the non-profit organizations against epilepsy in resource-poor areas, and capacity building of the staff in LAMICs.
- One well-managed organization in developed countries matches one underdeveloped organization in LAMICs.

- To define training courses in LAMICs sponsored by international NGOs. Eg. presently the ASEPA training courses sponsored by the Rotary Japan, which were held in ILAE chapters in Asian-Oceanian region.

- On-the-job training of staff working in epilepsy related organizations from LAMICs in well-managed organization in developed countries.

3.4 Promoting community management for PWE and set up bidirectional referral system in resourcepoor areas of the LAMICs: Continuing education to the non-specialists, general practitioners working in community level on detecting, diagnosis, treatment of epilepsy and observation of AED side effects, etc. and require them to manage PWE in scientific way. A bidirectional referral system is necessary supplement in accordance to the PWE community management. The two flow charts are shown here for reference. (see attachment Figs. 1 and 2)

3.5 Enhancement of the epilepsy awareness and control in minorities, migrants and refugees. Strengthening of awareness publicities, education programs,

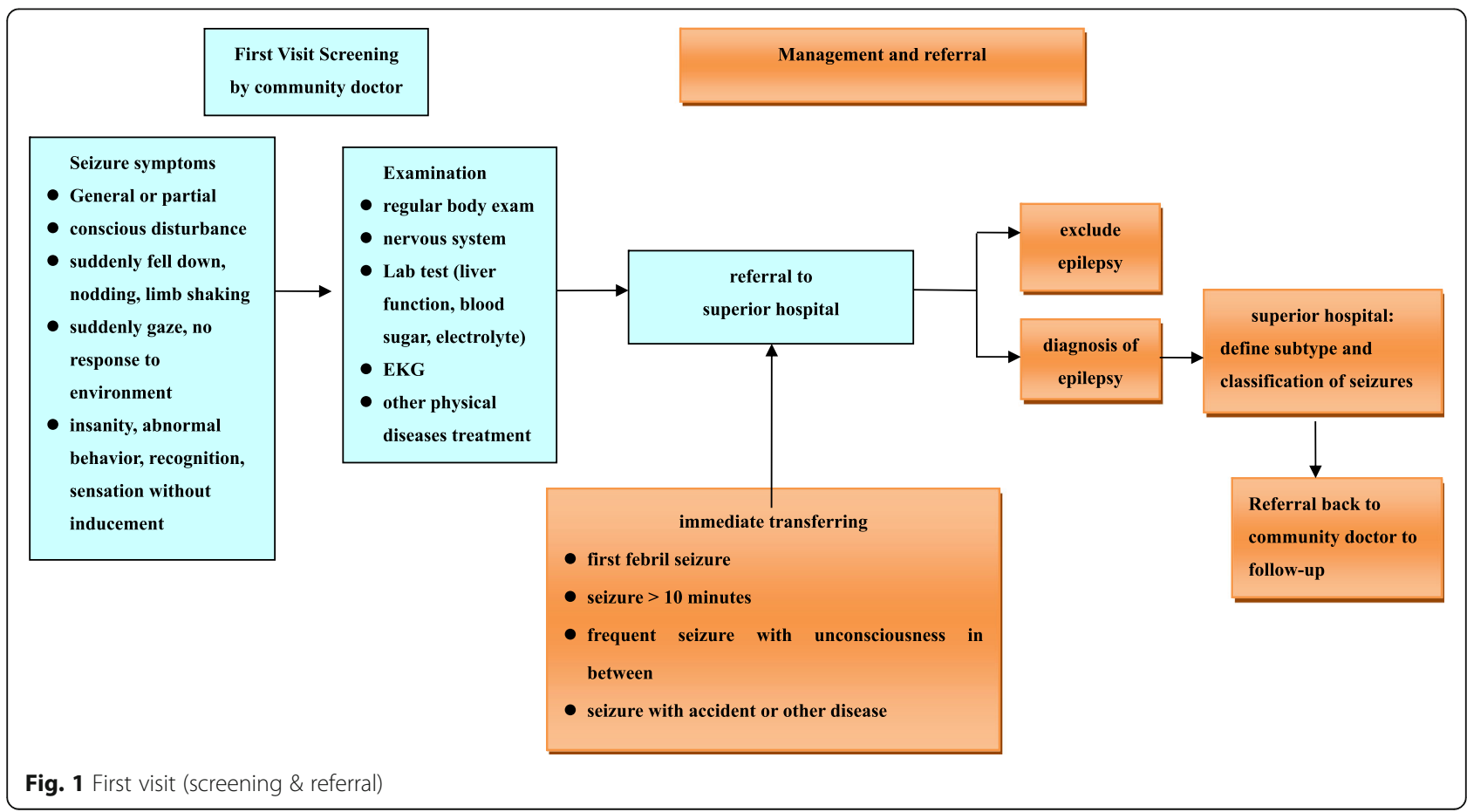




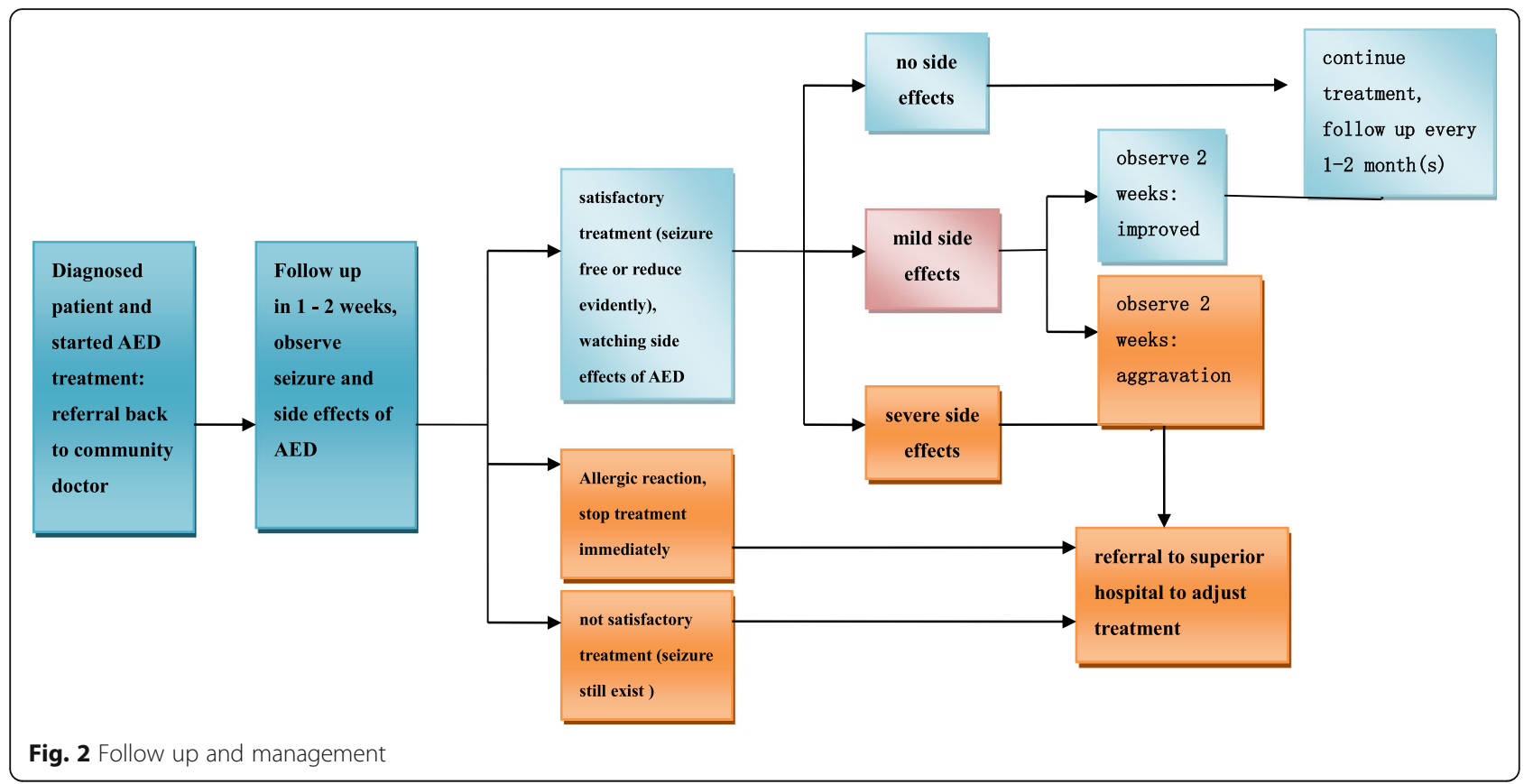

through every useful channels, mass media and public health system to non-specialists in epileptology, internal physicians, pediatricians, general practitioners, especially who work in rural, remote and economically backward areas.

To ensure public awareness and education about epilepsy, in particular in primary and secondary school students and teachers, in order to help to reduce the misconceptions, stigmatization and discrimination regarding people with epilepsy and their families that are widespread in many countries and regions.

These will need collaboration with health authorities in different level, other health-related social organizations, pharmaceutical industries, etc.

3.6 Fund raising and improving collaboration/ coordination with social societies including pharmaceutical industries to take public beneficial activities. We recommend "double winning" policy in the collaboration with pharmaceutical companies, means we never did commercial advertisement directly but stress industries' social responsibility, however, during those co-sponsored public activities, they may develop marketing territory naturally.

\section{Conclusion}

To prevent and control of epilepsy, the work in public health domain is of critical importance. This paper provides a brief review of the related actions worldwide and some recommendations on the strategies for epilepsy prevention \& control in public health aspects.

\section{Abbreviations}

AEDs: Anti-epileptic drugs; B\&R: The Belt and Road; GCAE: Global Campaign against Epilepsy; GOs: Governmental Organizations; GP: general practitioners; IBE: International Bureau for Epilepsy; ILAE: International League against Epilepsy; ILO: International Labour Organization; IOM: Institute of Medicine; LAMIC: low- and middle-income countries; MSR: Maritime Silk Road; NGOs: Non-Governmental Organizations; PAHO: Pan American Health Organization; PWE: People with eiplepsy; SREB: Silk Road Economic Belt; UNDP: United Nationa Development Programs; UNICEF: United Nations International Children's Emergency Fund; WHO: World Health Organization; WPRCM: WHO Western Pacific Regional Committee meeting

\section{Acknowledgements \\ NA}

Authors' contributions

Drafts and editing. All authors read and approved the final manuscript.

\section{Funding}

Not Applicable.

\section{Availability of data and materials \\ Yes}

Ethics approval and consent to participate

Not Applicable.

\section{Consent for publication}

Yes by the co-authors.

\section{Competing interests}

The authors declare that they have no competing interests.

\section{Author details}

${ }^{1}$ China Association Against Epilepsy, Beijing, China. ${ }^{2}$ Institute of Neurology, Huashan Hospital, Fudan University, Shanghai, China. ${ }^{3}$ Department of Pediatrics, Peking University First Hospital, Beijing, China. 
Received: 21 January 2019 Accepted: 18 June 2019

Published online: 25 July 2019

\section{References}

1. Baldwin R, et al. The epilepsy program in public health. Epilepsy Program, Am J Publ Health. 1953:43:452-9.

2. Koh HK, et al. Toward an integrated public health approach for epilepsy in the 21st century. Prev Chronic Dis. 2014;11:E146.

3. Cavanis T, et al. From global campaign to global commitment. Epilepsia. 2015;56(11):1651-7. https://doi.org/10.1111/epi.13192 Epub 2015 Sep 22.

4. Department of Mental Health and Substance Abuse, World Health

Organization, Programme for neurological diseases and neuroscience. Atlas: epilepsy care in the world. Geneva: WHO library cataloguing-in-publication data; 2005.

5. European Parliament 2009 - 2014. Epilepsy alliance Europe. Written Declar on Epilepsy. 2011;9:5.

6. Pan American Health Organization (PAHO/WHO). Report on epilepsy in Latin America and the Caribbean. Washington, D.C: PAHO; 2013.

7. WHO China Office. Epilepsy Management at Primary Health Level in rural China: A Global Campaign Against Epilepsy Demonstration Project, WHO Library Cataloguing in Publication Data, ISBN 978929061451 7, 2009.

Ready to submit your research? Choose BMC and benefit from:

- fast, convenient online submission

- thorough peer review by experienced researchers in your field

- rapid publication on acceptance

- support for research data, including large and complex data types

- gold Open Access which fosters wider collaboration and increased citations

- maximum visibility for your research: over $100 \mathrm{M}$ website views per year

At $\mathrm{BMC}$, research is always in progress.

Learn more biomedcentral.com/submissions 